\title{
Assessment of Cultural Competence Level among Academic Nursing Educators and associated Factors, Jeddah- Saudi Arabia
}

\author{
Ebtsam Aly Abou Hashish ${ }^{1,2^{*}}$, Hadeel Abdul Rahman AlJohani ${ }^{2}$, Ranin Ahmed Bahawi ${ }^{2}$ \\ ${ }^{1}$ Faculty of Nursing, Nursing Administration Department, Alexandria University, Egypt \\ ${ }^{2}$ College of Nursing - Jeddah, King Saud bin Abdul-Aziz University for Health Sciences, Kingdom of Saudi Arabia
}

\author{
DOI: $10.36348 /$ sjnhc.2020.v03i04.005 \\ | Received: 15.04.2020 | Accepted: 27.04.2020 | Published: 30.04.2020 \\ *Corresponding author: Dr. Ebtsam Aly Abou Hashish
}

\section{Abstract}

Background: Nurse educators have the potential to create a substantial effect on nursing students concerning cultural competence process. With this background, investigating the nurse educators' level of cultural competence can enhance how educators provide classroom and clinical instruction. Purpose: The main aim of this study was to assess the cultural competence level among academic nursing educators. Further to identify the associated factors to the overall cultural competence score of nurse educators. Methods: A descriptive correlational research design was conducted at College of Nursing, Jeddah- Saudi Arabia. All academic nurse educators were included in the study (N=45). Cultural Diversity Questionnaire for Nurse Educators-Revised [CDQNE-R] was proved reliable to measure study variables. Findings: The result of this study shows that the majority of academic nursing educators had a moderate level of overall cultural competence. They are committed to transcultural teaching behaviours as a motivator and predictor toward pursuing cultural competency. Nurse educators with more work experience, fluent of other language and integrating culture in their courses, were more culturally competent. Nationality doesn't affect culture competence. Discussion: Culture competency is an essential and basic skill for all nurse educators regardless of their nationalities and background. Cultural competence develops through practice and self-development and working experience which could have a positive influence on the cultural competence level of nurse educators. Conclusion: Professional cultural programs for Faculty need to be mandated and inclusive of the major constructs of cultural competence specifically culture encounter in clinical skills and interactions with individuals from culturally diverse backgrounds.

Keywords: Academic Nurse Educators, Cultural Competence, Nursing.

Copyright @ 2020: This is an open-access article distributed under the terms of the Creative Commons Attribution license which permits unrestricted use, distribution, and reproduction in any medium for non-commercial use (NonCommercial, or CC-BY-NC) provided the original author and source are credited.

\section{INTRODUCTION}

The Nursing profession endeavouring to move beyond a simple acknowledgment of diversity to integrating cultural issues in services and care provided to the patient/client [1]. Culture assumes a dynamic role in health perceptions, health behaviours and response to treatment so health care personnel should develop their cultural competence [2]. As more people from diverse cultures pursue access to health care resources, nurses are in charge of understanding, facilitating, and integrating traditional culture into modern approaches to health and nursing care [3]. Thus, Cultural competence becomes a crucial feature of nursing education and practice [4].

Cultural competence was commonly identified as "an ongoing process of seeking cultural awareness, cultural knowledge, cultural skill and cultural encounters in which the healthcare professional continuously strives to achieve the ability to effectively work within the cultural context of the patient, family, individual or community" [5]. Likewise, culturally competent nursing care aims to improve the quality of health care by reducing cultural disparities that arise when different cultures meet in the health care context [6].

The tenets of cultural competency should be infused throughout the nursing education curricula for nurses to meet the holistic needs of the patients. ${ }^{[4]}$ Hence, Nursing educational programs have a responsibility to adequately prepare their graduates to provide culturally competent care [7]. Culturally competent nursing education is the process of adjusting teaching and learning techniques in a learning environment that respects, values, empowers all members of the instructional team, including nursing students, educators and peers to accommodate the diversity. It starts with an assessment of the student's 
needs and integrates student interactions, curricula, inclass and online factors, and most importantly culturally competent Nursing educators committed to lifelong learning [8].

The main responsibility of nurse educators as a role model in nurturing students as future nurses capable of providing holistic care based on cultural competence is to dedicate themselves to intercultural care including all its aspects and to be competent in this area, here, Nurse educators have the potential to create a meaningful effect on nursing students concerning cultural competence process. Nurse educators have a role in incorporating culturally competent care in their educational programs to enable nursing students to identify beliefs and practices used to care for individuals from diverse cultures [9].

Creative nursing students need culturally competent nurse educators who reflect, value and honor the diverse characteristics of the student groups they teach. Unfortunately, not all nursing educational practices are culturally competent, and nursing students may believe that they're affected by nurse educators and student peers $[8,10,11]$. If nursing educators are successfully teaching and implementing culturally competent care practices in their curriculum and classroom instruction, nursing students will be aware of their own beliefs, practices, and perceptions and ability to identify some beliefs and practices used to serve [1]. In this context, the way nurse educators perceive and value their cultural competency is an important approach to ensure that that next generation of nurses is being educated regarding this critical aspect of nursing. And this is the intent for the current study framework.

\section{Conceptual Framework}

Campinha-Bacote's Process of Cultural Competence in the Delivery of Healthcare Services Model was selected as a conceptual framework of this study. According to this model, the process of cultural competence consists of five interrelated constructs that represent an interdependent relationship, namely; cultural encounter, cultural desire, Cultural awareness, cultural knowledge, and cultural skills. The main construct of the model and the beginning to cultural competence is Cultural encounter which refers to the process of being directly involved and engaged directly in cross-cultural interactions with people from culturally diverse backgrounds. Cultural encounter leads to seeking other constructs in the model $[5,12,13]$.

Cultural Desire reflects the inspiration of the healthcare providers to engage in the process of becoming culturally competent. Cultural awareness is an intentional, cognitive-learning process in which the health care providers are glancing at one's own cultural and professional beliefs, and become appreciative and sensitive to the values, beliefs, practices, lifeway, and problem-solving strategies of the patient's culture.
Cultural knowledge displays the process of investigating information to yield a foundation concerning cultural diversity. Cultural skills point out to the capability to systematically gather relevant meaningful data concerning the patient's health $[5,12,13]$.

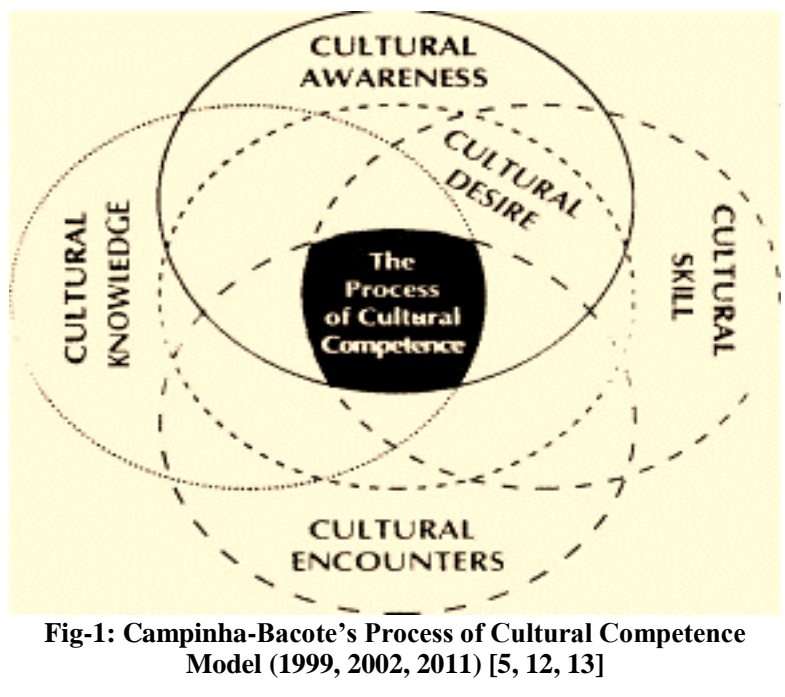

Based on this model, Sealey constructed the Cultural Diversity Questionnaire for Nurse EducatorsRevised [CDQNE-R] specifically to measure the cultural competence of nurse educators. [14] CDQNE-R comprises six constructs. Five of the constructs are based on Campinha-Bacote [5] culturally Competent Model of Care: cultural awareness, cultural knowledge, cultural skills, cultural encounters, and cultural desire. The sixth construct is, transcultural teaching behaviors, was added by Sealey in [14] and validated by [15] to assess the nurse educators' cultural behaviors and practices with students in the classroom and skills laboratory as well as clinical practice areas.

\section{The Significance of the Study}

Kingdom of Saudi Arabia (KSA) is growing into a more diverse country, and cultural competence becomes crucial [16]. The uniqueness of the Saudi culture is further connected with many expatriates residing in KSA contribute to a difference in religion, culture ,social values and languages which can usually create barriers between nurses and patients [16,17]. Hence, Nursing educators should be culturally knowledgeable and competent in order to teach students to identify behaviours, attitudes, and practices to embrace the differences of patients from various cultures. Greater diversity among health care professionals is associated with better educational experiences for all students while in training, which ensure that nurses can provide culturally relevant care [18].

As implied by Kardong-Edgren [19], cultural competency assessments can be used as a benchmark 
for Nurse Educators competence needs for Nurse educators' development. Also, it will provide a deeper understanding of the factors that influence the cultural competency of nursing educators who teach at bachelor programs. It is crucial that nurse educators understand their level of cultural competence and associated teaching behaviours [11].

\section{Problem Statement}

In the decades since cultural competency was introduced in research literature, previous studies have focused on transcultural nursing among nursing students. However, there have been few studies directed towards determining cultural competency levels among nurse educators in a different educational setting and showed that, nurse educators' low levels of cultural competence contribute to under-preparation of new nurses to provide culturally competent care $[11,14,19$ 21].

However, these studies have not addressed the influence of Nurse Educators demographic factors including level of education, exposure to different cultures, and international travel to Nurse Educators cultural competence [11]. Researchers highlighted that more research is required to test the relationship between Nurse Educators cultural competency levels and their demographic and professional variables $[15,21,22]$.

In addition, none of the researches have been conducted to specifically target the nursing educators' cultural competency assessment in KSA. With this background, investigating the nurse educators' level of the elements of cultural competence can improve how educators provide classroom and clinical instruction. Therefore, this study was conducted to fill this gap. The purpose of this study deemed essential, through identifying the difference between Saudi and non-Saudi nurse educators regarding culture competency level and the effect of associated factors on their perception, this can provide nurse educators with critical information about what they taught or not in the area of culture diversity and transcultural nursing which may direct curriculum revision and development $[10,11]$.

\section{AIM OF THE STUDY}

The main aim of this study was to assess the cultural competence level among academic nursing educators. Further to identify the associated factors to the overall cultural competence score of nurse educators working at College of Nursing, Jeddah- Saudi Arabia.

\section{Research Questions}

1. What is the overall cultural competence level of nursing educators?

2. What is the impact of transcultural-nursing teaching on the overall cultural competency level of nurse educators?
3. What are the associated factors to the overall cultural competence score of nursing educators?

\section{METHODOLOGY}

\section{Research Design and setting}

A descriptive correlational research design was conducted at College of Nursing- Jeddah (Con-J) which affiliated to King Saud Bin Abdul-Aziz University for Health Sciences. This college admits female Saudi national only and grant a Bachelor of Science in nursing after four years of academic studying and one year of internship. However, this college appointing nurse educators from diverse countries and cultures to teach nursing students not merely Saudi nurse educators, most commonly from (Egypt, India, South Africa, Malaysia, Pakistan, Jordon... etc.).

\section{Subject}

A convenient sample was incorporated all academic Nurse Educators who are enrolled in College of Nursing- Jeddah ( $\mathrm{N}=45)$ including; Associate Professors $(n=1)$, Assistant Professors $(n=22)$, Lecturers $(n=15)$, and Teaching Assistants $(n=7)$. These nurse educators representing diverse countries and cultures to teach nursing students.

\section{Data Collection Tool}

Cultural Diversity Questionnaire for Nurse Educators-Revised [CDQNE-R] developed by Sealey [14] and revised by Yates [15] was adapted to measure the cultural competence of nurse educators. It consisted of two sections:

1. The first section: included 15 questions asking about demographic and professional characteristics of Nurse Educators such as (age, country, highest degree, specialty, experience, fluency in other languages, cultural training, and cultural content .... etc.).

2. The second section: consists of 41 items organized into five subscales according to the component of cultural competence addressed namely: cultural encounters (six items); cultural desire (eight items); cultural awareness (eight items); cultural knowledge (eleven items); and cultural skills (eight items). In addition, eleven items that form the transcultural teaching behaviours subscale were embedded within the other five subscales. Responses were framed using a five-point Likert scale. Participants were asked to indicate a degree of agreement or disagreement, and a numerical value was assigned to each response: $5=$ strongly agree, and $1=$ strongly disagree. Total score ranged from 52 to 260 . The higher the score, the more culturally competent the nurse educator. Following was the metric for classifying the level of cultural competence based on survey 
results: 52-129; low level; $130-194=$ moderate level; $195-260=$ high level.

\section{Reliability and Validity}

The CDQNE-R was tested for internal reliability using Cronbach's alpha correlation coefficient, which proved it as highly reliable with the value of $(0.963)$. To determine the content validity, the CDQNE-R was reviewed by a jury of expert academic members. Accordingly, some items were adjusted for accuracy. In addition, a pilot study was conducted on 3 nursing educators who excluded from the study subjects to ensure the clarity and applicability of CDQNE-R.

\section{Data Collection Process}

After obtaining the Con-J research committee and King Abdullah International Medical Research Centre (KAIMRC) IRB approval, the questionnaire was distributed by the researchers to nursing educators who agreed to participate in the study on a predetermined time according to their workload and academic schedules.

\section{Data Analysis}

Data coded by the researchers and fed to the computer and analysed using IBM SPSS software package version 22. Frequency and percentages were employed for describing demographic characteristics. Descriptive statistics such as mean and standard deviation were applied to summarize the data. For comparison between numerical data, Student's t-test, and Analysis of Variance (ANOVA) F test were applied. Pearson correlation coefficient analysis (r) was used to prove the nature of the relationship between the different dimensions of Cultural Competence. Regression analysis $\left(\mathrm{R}^{2}\right)$ was employed to investigate the predictive power of the independent variable (Transcultural teaching behaviours) on the dependent variable (other cultural dimensions). $\mathrm{R}^{2}$ change was tested with F-test. A significant $F$ value for $R^{2}$ meant that the independent variable added significant prediction of the dependent variable. The level of significance was set as $p \leq .05$.
IRB approval was obtained from King Abdullah International Medical Research Centre (KAIMRC) (SP19/033/J). The student researchers explained the aim of the research to all participants. The privacy and confidentiality of data were maintained and guaranteed by obtaining participants' informed consent to participate in the research before data collection. The anonymity of participants was granted.

\section{RESULT}

The valid response rate in the current study was $98 \%$. The highest proportion of Nurse Educators $(71.1 \%)$ was non-Saudi and $44.4 \%$ of them in age category from 41 to 50 years old. Regarding the cultural background, $55.6 \%$ of academic nurse educators were from Asian country, while $24.4 \%$ were from African country. All Nurse Educators were working with fulltime employment. About one half $(51.1 \%)$ of the Nurse Educators are holding a doctorate degree, 33.3\% holding master's degree while $15.6 \%$ had bachelor's degree. About one third (35.6\%) of Nurse Educators have been teaching nursing for more than 15 years. The highest percentage $(60 \%)$ of the Nurse Educators are teaching undergraduate students, while $4.4 \%$ are teaching graduate students.

About one third (35.6\%) of the Nurse Educators their specialty in Adult Nursing, while the rest distributed across the other nursing specialities. Most of the Nurse Educators $(88.9 \%)$ have been living in a country with a different culture from their own for more than six months. Near half $(53.3 \%)$ of the Nurse Educators were fluent in a language other than English such as Arabic and other native language. The highest percentage $(75.6 \%)$ of the Nurse Educators have attend /completed an education program/workshop on Transcultural nursing/cultural competence in the past. Most Nurse Educators spend from 2 to 14 continuous education hours in these education programs/workshops. The majority $(86.7 \%, 73.3 \%)$ of the Nurse Educators include culture in their current teaching courses and assess the cultural beliefs and values toward educational learning in their students, respectively. About half $(51.3 \%)$ of the Nurse Educators occasionally mentioned cultural content in their current teaching program, while only $5.1 \%$ reported it in elective courses.

\section{Ethical Considerations}

Table-1: Distribution of Nurse Educators according to demographic and professional data $(\mathbf{N}=45)$

\begin{tabular}{|r|l|l|l|}
\hline $\mathbf{Q}$ & Demographic and Academic Data. & No. & $\boldsymbol{\%}$ \\
\hline $\mathbf{1}$ & Nationality & & \\
\hline & Non-Saudi & 32 & 71.1 \\
\hline & Saudi & 13 & 28.9 \\
\hline $\mathbf{2}$ & What is your age group? & & \\
\hline & 20 to 30 years & 1 & 2.2 \\
\hline & 31 to 40 years & 18 & 40.0 \\
\hline & 41 to 50 years & 20 & 44.4 \\
\hline & 51 to 60 years & 6 & 13.3 \\
\hline $\mathbf{3}$ & What is your cultural background classification and country? & & \\
\hline
\end{tabular}




\begin{tabular}{|c|c|c|c|}
\hline & Asian country & 25 & 55.6 \\
\hline & African country & 11 & 24.4 \\
\hline & Other & 9 & 20.0 \\
\hline \multirow[t]{3}{*}{4} & Which of the following best describes your employment status? & & \\
\hline & Full-time & 45 & 100.0 \\
\hline & Part-time & 0 & 0.0 \\
\hline \multirow[t]{4}{*}{5} & What is your highest degree attained? & & \\
\hline & Bachelor's & 7 & 15.6 \\
\hline & Masters & 15 & 33.3 \\
\hline & DNS/DNP/ PhD & 23 & 51.1 \\
\hline \multirow[t]{6}{*}{6} & How long have you been teaching Nursing? & & \\
\hline & Less than one year & 1 & 2.2 \\
\hline & $1-5$ years & 13 & 28.9 \\
\hline & $6-10$ years & 10 & 22.2 \\
\hline & $11-15$ years & 5 & 11.1 \\
\hline & More than 15 years & 16 & 35.6 \\
\hline \multirow[t]{8}{*}{7} & What is your nursing specialty area? (Please check all that apply) & & \\
\hline & Adult Nursing & 16 & 35.56 \\
\hline & Community Nursing & 5 & 11.11 \\
\hline & Pediatric Nursing & 7 & 15.56 \\
\hline & Maternity Nursing & 6 & 13.33 \\
\hline & Psychiatric Nursing & 2 & 4.44 \\
\hline & Nursing Management & 3 & 6.67 \\
\hline & Critical care Nursing & 6 & 13.33 \\
\hline \multirow[t]{3}{*}{8} & $\begin{array}{l}\text { Have you resided in a country with a different culture of your own for more than six } \\
\text { months? }\end{array}$ & & \\
\hline & Yes & 40 & 88.9 \\
\hline & No & 5 & 11.1 \\
\hline \multirow[t]{3}{*}{9} & Are you fluent in any language other than English? & & \\
\hline & Yes & 24 & 53.3 \\
\hline & No & 21 & 46.7 \\
\hline \multirow[t]{8}{*}{10} & If yes, please specify & & \\
\hline & Arabic and English & 14 & 58.3 \\
\hline & South Afrikaans & 1 & 4.2 \\
\hline & Arabic, French & 2 & 8.3 \\
\hline & Filipino & 2 & 8.3 \\
\hline & Urdu & 2 & 8.3 \\
\hline & ITALIAN, Urdu & 1 & 4.2 \\
\hline & Tagalogy, Arabic & 2 & 8.3 \\
\hline \multirow[t]{4}{*}{11} & At what level in your nursing college do you teach? (Please, indicate all that apply). & & \\
\hline & Undergraduate & 27 & 60.0 \\
\hline & Postgraduate & 2 & 4.4 \\
\hline & Both & 16 & 35.6 \\
\hline \multirow[t]{3}{*}{12} & $\begin{array}{l}\text { Have you attended /completed any education program/workshop on Transcultural } \\
\text { nursing/cultural competence in the past? }\end{array}$ & & \\
\hline & Yes & 11 & 24.4 \\
\hline & No & 34 & 75.6 \\
\hline \multirow[t]{3}{*}{13} & Do you include cultural content in your current teaching program? & & \\
\hline & Yes & 39 & 86.7 \\
\hline & No & 6 & 13.3 \\
\hline \multirow[t]{5}{*}{14} & If yes, what is the level of cultural content in your current teaching program? & & \\
\hline & Fully Integrated & 10 & 25.7 \\
\hline & Occasionally mentioned & 20 & 51.3 \\
\hline & Required course & 7 & 17.9 \\
\hline & Elective cultural course & 2 & 5.1 \\
\hline \multirow[t]{3}{*}{15} & Do you assess your students' cultural beliefs and values towards educational learning? & & \\
\hline & Yes & 33 & 73.3 \\
\hline & No & 12 & 26.7 \\
\hline
\end{tabular}

Table 2 reveals that the majority of academic nursing educators $(86.8 \%)$ had a moderate level of overall cultural competence represented by mean score $(73.55 \pm 13.50)$ while $6.6 \%$ of them had either high or low level of cultural competence. Regarding the perception of related dimensions of cultural competency, the highest mean was related to cultural awareness represented by a mean score $(78.68 \pm 16.70)$ followed by transcultural teaching behaviors $(74.44 \pm$ 15. 02), cultural desire $(74.31 \pm 15.22)$, cultural 
Knowledge (73.84 \pm 13.94$)$, and cultural skills (71.81 \pm

mean score represented by $(67.50 \pm 17.98)$.

15.23). While cultural encounter came as the lowest

Table-2: Mean score, SD and levels of cultural competence and its dimensions

\begin{tabular}{|c|c|c|}
\hline Cultural Competence dimensions & \multicolumn{2}{|c|}{$\begin{array}{c}\text { Mean percent score } \\
\text { Mean } \pm \text { SD. }\end{array}$} \\
\hline Cultural Encounters & \multicolumn{2}{|c|}{$17.98 \pm 67.50$} \\
\hline Cultural Desire & \multicolumn{2}{|c|}{$15.22 \pm 74.31$} \\
\hline Cultural Awareness & \multicolumn{2}{|c|}{$16.70 \pm 78.68$} \\
\hline Cultural Knowledge & \multicolumn{2}{|c|}{$13.94 \pm 73.84$} \\
\hline Cultural Skills & \multicolumn{2}{|c|}{$15.23 \pm 71.81$} \\
\hline Transcultural teaching behaviors & \multicolumn{2}{|c|}{$15.02 \pm 74.44$} \\
\hline Overall Cultural Competence & \multicolumn{2}{|c|}{$13.50 \pm 73.55$} \\
\hline \multicolumn{3}{|l|}{ Level of Cultural Competence } \\
\hline & No. & $\%$ \\
\hline Low level $(52-129)$ & 3 & 6.6 \\
\hline Moderate level $(130-194)$ & 39 & 86.8 \\
\hline High level $(195-260)$ & 3 & 6.6 \\
\hline
\end{tabular}

Levels of perceived Overall Cultural Competence

Low level (52 - 129), Moderate level (130 - 194), High level (195 -260)

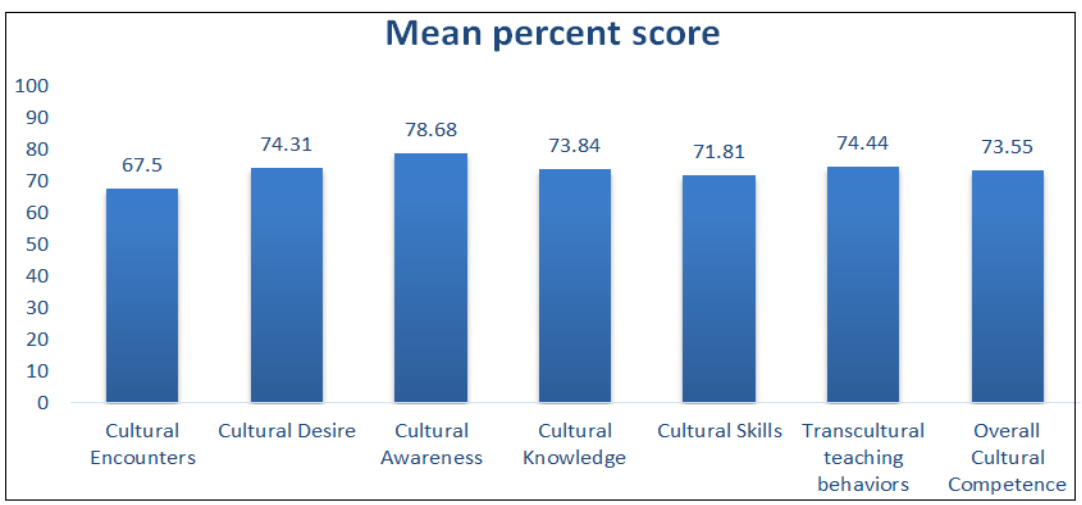

Fig-2: Mean score of cultural Competence and its Dimensions among Nurse Educators

Table-3 shows a strong positive correlation between overall cultural competence and each of its dimensions, including; Encounters ( $\mathrm{r}=0.767, \mathrm{p}<0.001)$, Desire ( $\mathrm{r}=0.876, \mathrm{p}<0.001)$, Awareness $(\mathrm{r}=0.876$, $\mathrm{p}<0.001)$, Knowledge $(\mathrm{r}=0.894, \mathrm{p}<0.001)$, Skills $(\mathrm{r}=$
$0.876, \mathrm{p}<0.001)$, and Transcultural teaching behaviors $(\mathrm{r}=0.961, \mathrm{p}<0.001)$. In addition, there is a positive correlation between all dimensions with each other were $\mathrm{p}<0.001$.

Table-3: Correlation between overall cultural competence and its dimensions

\begin{tabular}{|c|c|c|c|c|c|c|c|c|}
\hline $\begin{array}{r}\text { Cultural } \\
\text { Competence } \\
\text { dimensions } \\
\end{array}$ & & Encounters & Desire & Awareness & Knowledge & Skills & $\begin{array}{r}\text { Transcultural } \\
\text { teaching } \\
\text { behaviors } \\
\end{array}$ & $\begin{array}{r}\text { Overall cultural } \\
\text { competence }\end{array}$ \\
\hline \multirow{2}{*}{$\begin{array}{l}\text { Cultural } \\
\text { Encounters }\end{array}$} & $\mathrm{r}$ & & 0.624 & 0.579 & 0.640 & 0.532 & 0.654 & 0.767 \\
\hline & $\mathrm{p}$ & & $<0.001^{*}$ & $<0.001^{*}$ & $<0.001^{*}$ & $<0.001^{*}$ & $<0.001^{*}$ & $<0.001^{*}$ \\
\hline \multirow[t]{2}{*}{ Cultural Desire } & $\mathrm{r}$ & & & 0.807 & 0.663 & 0.709 & 0.884 & 0.876 \\
\hline & $\mathrm{p}$ & & & $<0.001^{*}$ & $<0.001^{*}$ & $<0.001^{*}$ & $<0.001^{*}$ & $<0.001^{*}$ \\
\hline \multirow{2}{*}{$\begin{array}{l}\text { Cultural } \\
\text { Awareness }\end{array}$} & $\mathrm{r}$ & & & & 0.728 & 0.751 & 0.914 & 0.899 \\
\hline & $\mathrm{p}$ & & & & $<0.001^{*}$ & $<0.001^{*}$ & $<0.001^{*}$ & $<0.001^{*}$ \\
\hline \multirow{2}{*}{$\begin{array}{l}\text { Cultural } \\
\text { Knowledge }\end{array}$} & $\mathrm{r}$ & & & & & 0.775 & 0.830 & 0.894 \\
\hline & $\mathrm{p}$ & & & & & $<0.001^{*}$ & $<0.001^{*}$ & $<0.001^{*}$ \\
\hline \multirow[t]{2}{*}{ Cultural Skills } & $\mathrm{r}$ & & & & & & 0.854 & 0.876 \\
\hline & $\mathrm{p}$ & & & & & & $<0.001^{*}$ & $<0.001^{*}$ \\
\hline \multirow{2}{*}{$\begin{array}{l}\text { Transcultural } \\
\text { teaching } \\
\text { behaviors }\end{array}$} & $\mathrm{r}$ & & & & & & & 0.961 \\
\hline & $\mathrm{p}$ & & & & & & & $<0.001^{*}$ \\
\hline
\end{tabular}

r: Pearson correlation coefficient

*: Statistically significant at $\mathrm{p} \leq 0.05$ 
In addition, Table-4 reveals the regression coefficient value between Transcultural teaching behaviors as independent variable and cultural competence, and its dimensions as dependent variables where $\mathrm{R}^{2}=0.923$. This means that Transcultural teaching behaviors significantly contributes to the prediction of $92.3 \%$ of the explained variance of cultural competence where the regression model is significant $(\mathrm{F}=514.706, \mathrm{p}<0.001)$. Also, Transcultural teaching behaviors has the predictive power of other dimensions including Encounters $\left(\mathrm{R}^{2}=0.427,(42.7 \%)\right.$, Desire $\left(\mathrm{R}^{2}=0.781\right.$, $(78.1 \%)$, Awareness $\left(\mathrm{R}^{2}=0.836\right.$, (83.6\%), Knowledge $\left(\mathrm{R}^{2}=0.690, \quad(69.0 \%), \quad\right.$ and Skills $\left(\mathrm{R}^{2}=0.729,(72.9 \%)\right.$ where the regression model is significant $(\mathrm{p}<0.001)$.

Table-4: Multiple Regressions Analysis between Transcultural teaching behaviors with culture competency dimensions

\begin{tabular}{|l|l|l|l|l|l|}
\hline Cultural Competence dimensions & $\mathbf{R}^{2}$ & $\mathbf{F}(\mathbf{p})$ & $\mathbf{B}$ & Beta & $\mathbf{t}(\mathbf{p})$ \\
\hline Cultural Encounters & 0.427 & $32.069\left(<0.001^{*}\right)$ & 0.782 & 0.654 & $5.633\left(<0.001^{*}\right)$ \\
\hline Cultural Desire & 0.781 & $153.053\left(<0.001^{*}\right)$ & 0.895 & 0.884 & $12.371\left(<0.001^{*}\right)$ \\
\hline Cultural Awareness & 0.836 & $219.016\left(<0.001^{*}\right)$ & 1.016 & 0.914 & $14.799\left(<0.001^{*}\right)$ \\
\hline Cultural Knowledge & 0.690 & $95.565\left(<0.001^{*}\right)$ & 0.771 & 0.830 & $9.776\left(<0.001^{*}\right)$ \\
\hline Cultural Skills & 0.729 & $115.414\left(<0.001^{*}\right)$ & 0.865 & 0.854 & $10.743\left(<0.001^{*}\right)$ \\
\hline Overall Cultural Competence & $\mathbf{0 . 9 2 3}$ & $\mathbf{5 1 4 . 7 0 6}\left(<\mathbf{0 . 0 0 1}{ }^{*}\right)$ & $\mathbf{0 . 8 6 3}$ & $\mathbf{0 . 9 6 1}$ & $\mathbf{2 2 . 6 8 7}\left(<\mathbf{0 . 0 0 1}{ }^{*}\right)$ \\
\hline
\end{tabular}

R2: Coefficient of determination

B: Unstandardized Coefficients Beta: Standardized Coefficients

t: t-test of significance

F: F for ANOVA test

*: Statistically significant at $\mathrm{p} \leq 0.05$

Concerning the Relationship between academic nurse educators' cultural competence and their demographics and work-related characteristics, the result represents no significant relationship between academic nurse educators culture competency and their demographic and academic characteristics except for their age with culture encounter; language fluency with cultural awareness and level of integrating cultural content with cultural desire. Farther, there is no significant difference between Saudi and non-Saudi nurse educators regarding their perception of overall cultural competence $(\mathrm{t}=0.001, \mathrm{p}=0.999)$ as well as the related dimensions.

On the other hand, the result displays that age group that ranged from 51 to 60 years old had the highest mean culture encounter dimension score $(\mathrm{F}=3.201$, and $\mathrm{P}=0.033)$. Also, those who are fluent had the highest awareness of culture competency mean $(83.46 \pm 10.36)$ in comparison to those not fluent in other language $(\mathrm{t}=2.135$, and $\mathrm{P}=0.038)$. In addition, Nurse educators who integrated culture as a required cultural content of their courses had the highest cultural desire mean in comparison to others $(\mathrm{F}=2.906$, and $\mathrm{P}=0.047)$. See supplementary tables 1 and 2 for the values.

\section{DISCUSSION}

Cultural competence of nursing educators plays an important part in offering culturally competent care at local, national and global environments. Nurse educators, nursing students, and nurses have to achieve an ample level of cultural competence [9].

The result of this study shows that the majority of academic nursing educators had a moderate level of cultural competence with the highest mean related to cultural awareness followed by transcultural teaching behaviours while cultural encounters came as the lowest mean. Cultural awareness subscale in this study was the strongest predictor of overall cultural competency level. This indicates that study participants perceived themselves as culturally aware and respect the cultural diversity. Similarly, Campinha-Bacote emphasized that cultural awareness is crucial to create consciousness and a respectful environment of cultural diversity within nursing practice and education [23]. If nurse educators are reluctant to get involved in cultural awareness, it may not be possible that students are willing to offer culture sensitive care [7,9]. While Kardong-Edgren and Campinha-Bacote identified that lack of cultural awareness is a major barrier toward providing culturally competent education and care [24]. The result of this study goes in the same line with Baghdadi and Ismaile and Ume-Nwagbo who revealed that most nurse educators have a moderate level of cultural competence $[10,22]$. Also, Yates, showed the highest index was cultural awareness [15].

On the other hand, Cultural encounter dimension has relatively the lowest mean compared with the rest of the cultural competence constructs in this study. This result might be indicative that nurse educators could have a low level of opportunities to face-to-face interactions with individuals from diverse backgrounds as they educate mainly Saudi nursing students. In the same line, Baghdadi indicated that study participants are at the low point of cultural encounter [11]. Other studies reported cultural encounter score as the lowest dimension [14,15].

In this respect, Liu, Mao, and Barnes-Willis showed that exposure to cultural content and to diverse populations has a major impact on cultural competence level of graduating nurses [25]. Researches proved the need for professional development programs for nursing faculty in the area of cultural diversity and the 
important need for hiring and retaining a culturally diverse nursing educators $[11,15]$. Nursing educators should engage in continuing cultural education activities that would improve their cultural competence so they can be effective teachers, mentors, and role models for their students [22].

The result of this study shows that there is a strong positive correlation between overall cultural competence and each of its dimensions. This could be indicative of the necessity of integrating all cultural dimensions to achieve cultural proficiency. As de Beer and Chipps stated, cultural competence can be achieved in nursing education by developing a taxonomy that includes being culturally aware, motivated, sensitive, skilful, and interactive [26].

Findings also highlight that Transcultural teaching behaviours significantly contributes to the prediction of $92.3 \%$ of the explained variance of cultural competence. Transcultural teaching relates explicitly to the educators' behaviours and practices with students in the classroom and skills laboratory as well as clinical practice areas. The higher used transcultural teaching, the higher cultural competence. This finding is noteworthy in the current study as it indicated that faculty commitment to transcultural teaching serves as a motivator toward pursuing cultural competency. Similar findings were reported by Baghdadi and Burke [11,27] who declared that transcultural teaching behaviours subscale has predicting power of the variability in overall cultural competence score. However, the findings of this study contrast with those reported by Sealey and Yates who found that their participants only agree with some items related to including cultural content in teaching $[14,15]$.

Moreover, the findings pointed out that there were significant correlations between some academic characteristics with some dimensions of cultural competence. Specifically, older nurse educators had the highest culture encounter mean, and those who were fluent in any language rather than English had the highest culture awareness. In addition, those nurse educators who integrated culture as a required cultural content in their courses reflect their high cultural desire. This could be interpreted that nurse educators who had more work experience and gained the fluency of other language and used to integrate culture diversity in their courses were more competent. Correspondingly, Baghdadi and Ismaile and Baghdadi supported that predictors of language spoken other than English, including cultural content in the current nursing program, level of incorporating cultural content incurrent program positively influenced the mean of the overall cultural competence [10,11]. Also, Sargent et al., found that cultural competence levels of nurse educators are affected by their knowing a foreign language, getting involved in exchange programs and visiting a foreign country [28].
What is more, there is no significant difference between Saudi and non-Saudi nurse educators regarding their perception of overall cultural competence and its dimensions. This result may be attributed to the notion that culture competency is a fundamental and primary skills for all nurse educators regardless of their nationalities and background. The presence of multiple nationalities, with a different language, could play a major role to increasing the cultural interaction and Transcultural teaching behaviours, which could be reflected on all academic nursing educators. In the same vein, Kardong-Edgren showed that exposure to another culture were the most frequently mentioned methods of increasing cultural competency [19]. In this regard, Reneau suggested the need to mandate cultural competency training BSN degree nursing faculty, whether it occurs during their orientations or as part of nurse-educator curricula at the graduate levels [29]. Also, Liu, Mao and Barnes-Willi recommend the need for nurse educators continue to consolidate cultural concepts and experiences in the nursing curriculum [25].

\section{Strengths and Limitation}

This study could be considered the first national study that assessed the cultural competence of nursing faculty teaching in BSN programs in KSA. it may provide a deeper understanding of the factors affecting the cultural competence level of BSN faculty and provide suggestions for nursing education and recognize the training needs of nursing faculty in the area of cultural competence. However, several limitations should be addressed. First, the study was conducted on female nurse educators in one college of KSA so the results of the study cannot be generalized. It is yet important to replicate the results with different samples in various settings and cities. Second, participants of this study were not asked about their religious affiliation, which might affect their cultural competence level. Last, using self-reporting instruments for data collection increased the risk for bias.

\section{CONCLUSION}

This study addresses the level of cultural competence of nurse educators teaching in BSN nursing programs in the KSA and examines the contributors and demographic factors that may influence their cultural competence level. Based on the results of this study, we can say that the majority of academic nursing educators had a moderate level of overall cultural competence. Study participants are culturally aware and respectful to cultural diversity issues, but they need to enhance their cultural encounters, which was the least compared with the other cultural constructs. One of the main findings of the current study as it showed up that faculty commitment to transcultural teaching behaviours acts as a motivator and predictor toward pursuing cultural competency. Nurse educators, who had higher work experience, gained the fluency of other language and used to assimilate culture diversity in their courses, 
were more culturally competent. This entails that cultural competence develops through practice and selfdevelopment and working experience, which could have a reasonable influence on the cultural competence level of nurse educator. Culture competency is a fundamental and basic skill for all nurse educators regardless of their nationalities and background.

\section{Implications and Recommendations}

The findings of this study have important implications. Therefore, the following recommendations are suggested:

- Nursing Faculty's administrators should provide a training workshops about cultural diversity and competency for the new academic nursing educators to understand better about the diverse cultures which they will be dealing with and what are the behaviours which are not excepted in each culture.

- The professional cultural development programs for Faculty need to be mandated and should be more comprehensive of the major constructs of cultural competence specifically culture encounter issues in clinical skills and face-to-face interactions with individuals from culturally diverse backgrounds. The training should occur during orientations, and as an annual competency check.

\section{For Future Research}

- Giving the increasing demand of culturally competent nurses, further studies need to compare cultural competence levels between nurse educators and their students since studies revealed that faculty members' cultural competence level affects students' cultural competence level.

- More longitudinal investigations are required to focus on nursing students at the start of their program of study, after graduation, and after working for some time. A longitudinal study would help to assess their cultural competence levels at each stage and identify contributing factors at the three phases of the study.

- A qualitative research is recommended to address factors that contribute to cultural competence from faculty perspectives and to identify the best educational strategies to teach cultural competency in nursing programs.

\section{Conflicts of Interest Disclosure}

The authors declare that there is no conflict of interest.

\section{Funding}

The authors disclosed no receipt of any financial support for the research, authorship, and/or publication of this article.

\section{REFERENCES}

1. Wittig, D. R. (2004). Knowledge, Skills, and Attitudes of Nursing Students Regarding Culturally Congruent Care of Native Americans. Journal Transcult Nurs, 15(1),54-61.

2. Gözum, S., Tuzcu, A., \& Kirca, N. (2016). Validity and reliability of the Turkish version of the nurse cultural competence scale. Journal Transcult Nurs, 27(5),487-495.

3. Darnell, L. K., \& Hickson, S. V. (2015). Culturally competent patient-centered nursing care. Nurs Clin N Am, 50, 99-108.

4. Hartman, D. S. (2017). Self-Efficacy and Cultural Competency Assessment of the Associate Degree Nursing Student. Published Dissertation, Walden University.

5. Campinha-Bacote, J. (1999). A model and instrument for addressing cultural competence in health care. Journal Nurs Educ, 38 (5),203-207.

6. Almutairi, A. F., McCarthy, A., \& Gardner, G. E. (2015). Understanding cultural competence in a multicultural nursing workforce: registered nurses experiences in Saudi Arabia. Journal Transcult Nurs, 26 (1),16-23.

7. Von Ah, D., \& Cassara, N. (2013). Perceptions of cultural competency of undergraduate nursing students. Open Journal of Nursing, 3,182-185.

8. Smith, L. (2018). A nurse educator's guide to cultural competence. Made Incredibly Easy! 16(2), 19-23.

9. Montenery, S., Jones, A., Perry, N., Ross, D., \& Zoucha, R. (2013). Cultural competence in nursing faculty: a journey, not a destination. Journal of professional nursing, 29(6), 51-57.

10. Baghdadi, N., \& Ismaile, S. (2018). Cultural competency of nursing faculty teaching in baccalaureate nursing programs in the United States. Australasian Medical Journal, 11(2),126134.

11. Baghdadi, N. (2014). Cultural Competency of Nursing Faculty. Teaching in Baccalaureate Nursing Programs in the U.S. Northeastern University, Boston, Massachusetts, USA.

12. Campinha-Bacote, J. (2002). The process of cultural competence in the delivery of healthcare services: A model of care. Journal of Transcultural Nursing, 13(3), 181-184.

13. Campinha-Bacote, J. (2011). Delivering patientcentered care in the midst of a cultural conflict: The role of cultural competence. Online Journal of Issues of Nursing, 16(2), 1-12.

14. Sealey, L. J. (2003). Cultural competence of faculty of baccalaureate nursing programs. Unpublished doctoral dissertation, Louisiana State University and Agricultural \& Mechanical College.

15. Yates, V. M. (2009). Cultural competence levels of Ohio associate degree nurse educators. In: Baghdadi, N. (2014). Cultural Competency of Nursing Faculty. Teaching in Baccalaureate 
Nursing Programs in the U.S. Northeastern University, Boston, Massachusetts, USA.

16. Halabi, J., \& de Beer, J. (2018). Exploring the cultural competence of undergraduate nursing students in Saudi Arabia. Nurse Education Today, 62, 9-15.

17. AlYami, M. S., \& Watson, R. (2014). An overview of nursing in Saudi Arabia. J Health Spec, 2(1), 10-12. http://dx.doi.org/10.4103/1658600X.126058

18. Institute of Medicine. (2011). The future of nursing: Leading change, advancing health. The National Academies Press, Washington DC.

19. Kardong-Edgren, S. (2007). Cultural Competence of Baccalaureate Nursing Faculty. Journal of Nursing Education, 46(8), 360-366.

20. Kardong-Edgren, S., Bond, M. L., Schlosser, S., Cason, C., Jones, M. E., Warr, R., \& Strunk, P. (2005). Cultural attitudes, knowledge, and skills of nursing faculty toward patients from four diverse cultures. Journal of Professional Nursing, 21(3), 175-182.

21. Sealey, L. J., Burnett, M., \& Johnson, G. (2006). Cultural competence of baccalaureate nursing faculty: are we up to the task? Journal of Cultural Diversity, 13(3),131-140.

22. Ume-Nwagbo, P. N. (2009). Relationship between nurse educators' cultural competence and ethnic minority nursing students' recruitment and graduation. In: Baghdadi, N. (2014). Cultural Competency of Nursing Faculty. Teaching in Baccalaureate Nursing Programs in the U.S.
Northeastern University, Boston, Massachusetts, USA.

23. Campinha-Bacote, J. (2010). The process of cultural competence in the delivery of healthcare services.. Retrieved from www.transculturalcare.net/Cultural_Competence_ Model.htm

24. Kardong-Edgren, S., \& Campinha-Bacote, J. (2008). Cultural competency of graduating US Bachelor of Science nursing students. Contemporary Nurse: A Journal For The Australian Nursing Profession, 28(1-2), 37-44

25. Liu, L., Mao, C., \& Barnes-Willis, L. E. A. (2008). Cultural self-efficacy of graduating baccalaureate nursing students in a state funded university in the Silicon Valley. Journal of Cultural Diversity, 15(3), 100-107.

26. De Beer, J., \& Chipps, J. (2014). A survey of cultural competence of critical care nurses in KwaZulu-Natal. SAJCC, 30 (2), 50-54.

27. Burke, P. M. (2011). Cultural competency of associate degree nursing faculty. Unpublished 3449380, Capella University, United States -Minnesota.

28. Sargent, S. E., Sedlak, C. A., \& Martsolf, D. S. (2005). Cultural Competence among Nursing Students and Faculty. Nurse Education Today 25(3), 214-221.

29. Reneau, M. (2013). Teaching nurses sight unseen: Comparing the cultural competency among oncampus and online baccalaureate degree nursing faculty. Journal of Transcultural Nursing, 24(1), 78-85.

Supplementary Table-1: Relationship between academic nurse educators' cultural competence and their demographics and work-related characteristics

\begin{tabular}{|c|c|c|c|c|c|c|c|}
\hline & Encounters & Desire & Awareness & Knowledge & Skills & $\begin{array}{r}\text { Transcultural } \\
\text { teaching } \\
\text { behaviors } \\
\end{array}$ & $\begin{array}{r}\begin{array}{r}\text { Overall } \\
\text { cultural } \\
\text { competence }\end{array} \\
\end{array}$ \\
\hline \multicolumn{8}{|c|}{ What is your age group? years } \\
\hline 20 to 30 & 91.67 & 84.38 & 84.38 & 97.73 & 93.75 & 93.18 & 90.85 \\
\hline 31 to 40 & $70.60 \pm 13.82$ & $76.22 \pm 13.26$ & $80.38 \pm 14.33$ & $74.62 \pm 12.50$ & $71.70 \pm 15.02$ & $75.13 \pm 12.65$ & $74.90 \pm 10.55$ \\
\hline 41 to 50 & $60.0 \pm 19.93$ & $72.03 \pm 17.19$ & $76.41 \pm 20.94$ & $70.45 \pm 15.71$ & $70.47 \pm 16.14$ & $71.70 \pm 17.64$ & $70.40 \pm 16.29$ \\
\hline 51 to 60 & $79.17 \pm 12.08$ & $74.48 \pm 16.23$ & $80.21 \pm 7.03$ & $78.79 \pm 6.99$ & $72.92 \pm 13.36$ & $78.41 \pm 11.74$ & $77.13 \pm 9.69$ \\
\hline $\mathbf{F}(\mathbf{p})$ & $3.201\left(0.033^{*}\right)$ & $0.373(0.773)$ & $0.229(0.876)$ & $1.724(0.177)$ & $0.741(0.534)$ & $0.885(0.457)$ & $1.122(0.351)$ \\
\hline \multicolumn{8}{|c|}{ What is your cultural background classification and country? } \\
\hline Asian, country & $67.0 \pm 17.76$ & $72.0 \pm 14.45$ & $75.38 \pm 18.87$ & $71.64 \pm 14.60$ & $70.13 \pm 14.52$ & $71.0 \pm 16.33$ & $71.46 \pm 14.59$ \\
\hline African, country & $61.74 \pm 20.65$ & $74.43 \pm 20.05$ & $83.52 \pm 14.26$ & $72.93 \pm 11.38$ & $73.01 \pm 14.34$ & $77.48 \pm 12.63$ & $73.67 \pm 12.59$ \\
\hline Other & $75.93 \pm 13.14$ & $80.56 \pm 9.21$ & $81.94 \pm 11.56$ & $81.06 \pm 13.87$ & $75.0 \pm 19.07$ & $80.30 \pm 12.40$ & $79.20 \pm 10.75$ \\
\hline $\mathbf{F}(\mathbf{p})$ & $1.605(0.213)$ & $1.048(0.360)$ & $1.131(0.332)$ & $1.584(0.217)$ & $0.374(0.690)$ & $1.609(0.212)$ & $1.093(0.345)$ \\
\hline \multicolumn{8}{|c|}{ What is your highest degree attained? } \\
\hline Bachelor's & $69.05 \pm 15.0$ & $75.45 \pm 8.92$ & $80.36 \pm 10.32$ & $75.0 \pm 10.82$ & $76.34 \pm 11.95$ & $75.97 \pm 10.40$ & $75.52 \pm 9.49$ \\
\hline Masters & $71.39 \pm 15.66$ & $72.92 \pm 11.31$ & $74.58 \pm 11.68$ & $75.0 \pm 13.90$ & $72.29 \pm 13.51$ & $72.88 \pm 14.26$ & $73.46 \pm 12.03$ \\
\hline DNS/DNP/ PhD & $64.49 \pm 20.21$ & $74.86 \pm 18.93$ & $80.84 \pm 20.61$ & $72.73 \pm 15.20$ & $70.11 \pm 17.29$ & $75.0 \pm 17.02$ & $73.01 \pm 15.68$ \\
\hline $\mathbf{F}(\mathbf{p})$ & $0.689(0.508)$ & $0.094(0.911)$ & $0.669(0.517)$ & $0.144(0.867)$ & $0.449(0.641)$ & $0.128(0.880)$ & $0.090(0.914)$ \\
\hline \multicolumn{8}{|c|}{ How long have you been teaching Nursing? } \\
\hline Less than one year & 83.33 & 75.0 & 81.25 & 95.45 & 100.0 & 86.36 & 87.80 \\
\hline $1-5$ years & $71.79 \pm 10.37$ & $74.76 \pm 7.91$ & $78.37 \pm 10.32$ & $76.40 \pm 11.90$ & $69.71 \pm 9.91$ & $74.13 \pm 7.63$ & $74.48 \pm 7.56$ \\
\hline $6-10$ years & $64.58 \pm 21.63$ & $75.63 \pm 20.30$ & $76.56 \pm 26.61$ & $75.45 \pm 19.37$ & $72.81 \pm 20.42$ & $74.55 \pm 23.10$ & $73.60 \pm 20.71$ \\
\hline $11-15$ years & $66.67 \pm 18.87$ & $66.88 \pm 11.18$ & $70.63 \pm 14.92$ & $65.0 \pm 10.61$ & $66.25 \pm 18.14$ & $65.45 \pm 13.10$ & $66.95 \pm 11.91$ \\
\hline More than 15 years & $65.10 \pm 21.02$ & $75.39 \pm 18.11$ & $82.62 \pm 14.39$ & $72.16 \pm 11.57$ & $72.85 \pm 13.96$ & $76.70 \pm 14.41$ & $73.93 \pm 12.82$ \\
\hline $\mathbf{F}(\mathbf{p})$ & $0.495(0.739)$ & $0.319(0.863)$ & $0.537(0.709)$ & $1.346(0.270)$ & $1.127(0.357)$ & $0.677(0.612)$ & $0.573(0.683)$ \\
\hline \multicolumn{8}{|c|}{ What is your nursing specialty area? } \\
\hline Adult & $64.84 \pm 11.98$ & $73.24 \pm 13.11$ & $77.93 \pm 14.0$ & $72.02 \pm 11.13$ & $68.55 \pm 11.77$ & $72.30 \pm 12.23$ & $71.68 \pm 10.27$ \\
\hline Community & $73.33 \pm 14.91$ & $81.88 \pm 10.69$ & $88.75 \pm 8.15$ & $74.55 \pm 6.10$ & $70.63 \pm 1.71$ & $80.91 \pm 3.45$ & $77.80 \pm 5.51$ \\
\hline
\end{tabular}


Ebtsam Aly Abou Hashish et al; Saudi J Nurs Health Care, April., 2020; 3(4): 140-150

\begin{tabular}{|c|c|c|c|c|c|c|c|c|c|c|c|}
\hline Pediatric & $55.36 \pm 27.82$ & \multicolumn{2}{|c|}{$65.18 \pm 20.76$} & \multicolumn{2}{|c|}{$66.96 \pm 27.94$} & \multicolumn{2}{|c|}{$68.18 \pm 21.40$} & \multicolumn{2}{|c|}{$68.75 \pm 21.73$} & $66.56 \pm 24.43$ & $65.59 \pm 22.39$ \\
\hline Maternity & $65.28 \pm 15.06$ & \multicolumn{2}{|c|}{$72.92 \pm 7.03$} & \multicolumn{2}{|c|}{$80.21 \pm 7.82$} & \multicolumn{2}{|c|}{$76.89 \pm 9.36$} & \multicolumn{2}{|c|}{$78.13 \pm 10.08$} & $76.52 \pm 8.46$ & $75.30 \pm 7.41$ \\
\hline Psychiatric & \multirow{2}{*}{$\frac{68.75 \pm 20.62}{60.42 \pm 20.62}$} & \multicolumn{2}{|c|}{$93.75 \pm 8.84$} & \multicolumn{2}{|c|}{$98.44 \pm 2.21$} & \multicolumn{2}{|c|}{$79.55 \pm 12.86$} & \multicolumn{2}{|c|}{$96.88 \pm 4.42$} & $90.91 \pm 3.21$ & $87.80 \pm 1.72$ \\
\hline $\begin{array}{r}\text { Nursing } \\
\text { Management }\end{array}$ & & \multicolumn{2}{|c|}{$85.94 \pm 15.47$} & \multicolumn{2}{|c|}{$90.63 \pm 8.84$} & \multicolumn{2}{|c|}{$71.59 \pm 4.82$} & \multicolumn{2}{|c|}{$71.88 \pm 4.42$} & $82.95 \pm 4.82$ & $76.52 \pm 0.43$ \\
\hline Critical care & \multirow{2}{*}{$\begin{array}{l}74.54 \pm 18.92 \\
1.052(0.410) \\
\end{array}$} & \multicolumn{2}{|c|}{$74.31 \pm 16.07$} & \multicolumn{2}{|c|}{$77.43 \pm 14.47$} & \multicolumn{2}{|c|}{$75.0 \pm 14.90$} & $71.53 \pm$ & .54 & $73.74 \pm 16.67$ & $74.59 \pm 15.07$ \\
\hline$F(p)$ & & $1.446(0.2$ & 212) & 1.579 & $168)$ & 0.517 & $817)$ & 1.226 & & $1.054(0.409)$ & $0.960(0.472)$ \\
\hline & & Ha & ve you & resided i & cour & y with a & differ & t culture & you & own for more th & n six months? \\
\hline Yes & $69.48 \pm 14.38$ & $75.86 \pm 12$ & 2.11 & $80.55=$ & 2.41 & $75.28 \pm$ & 11.49 & $72.19 \pm$ & .95 & $75.63 \pm 11.67$ & $74.97 \pm 9.98$ \\
\hline No & $51.67 \pm 34.43$ & $61.88 \pm 30$ & 0.01 & $63.75=$ & 35.40 & $62.27 \pm$ & 25.74 & $68.75 \pm$ & & $65.0 \pm 32.08$ & $62.20 \pm 29.16$ \\
\hline$t(p)$ & $1.144(0.314)$ & $1.032(0.3$ & 358) & 1.053 & .350) & 1.116( & 324) & 0.253 & 12) & $0.734(0.502)$ & $0.973(0.384)$ \\
\hline Cont. & Encounters & Desire & & areness & & wledge & & Skills & & $\begin{array}{r}\text { Transcultural } \\
\text { ching behaviors }\end{array}$ & $\begin{array}{r}\text { Overall } \\
\text { score }\end{array}$ \\
\hline & & & & & & & & e you flu & in a & y language othe & than English? \\
\hline Yes & $70.66 \pm 8.19$ & $76.56 \pm 10.71$ & 83. & $6 \pm 10.36$ & 77.1 & \pm 10.86 & & \pm 11.24 & & $77.75 \pm 9.21$ & $76.40 \pm 8.05$ \\
\hline No & $63.89 \pm 24.66$ & $71.73 \pm 19.10$ & 73.2 & $1 \pm 20.77$ & 70.6 & \pm 16.22 & 71. & \pm 19.08 & & $70.67 \pm 19.26$ & $70.30 \pm 17.47$ \\
\hline$t(p)$ & $1.201(0.241)$ & $1.028(0.312)$ & 2.13 & $\left(0.038^{*}\right)$ & 1.75 & $(0.086)$ & 0.26 & (0.792) & & $1.537(0.136)$ & $1.469(0.153)$ \\
\hline & & & & & & & & what ler & 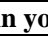 & nursing colleg & do you teach? \\
\hline Undergraduate & $70.68 \pm 15.09$ & $74.31 \pm 12.14$ & 77. & $8 \pm 13.24$ & & $9 \pm 14.0$ & 72.8 & \pm 14.88 & & $74.41 \pm 13.37$ & $74.50 \pm 12.38$ \\
\hline Graduate & $66.67 \pm 5.89$ & $70.31 \pm 28.73$ & & $3.13 \pm 0.0$ & & $6 \pm 4.82$ & & $0 \pm 4.42$ & & $72.73 \pm 9.64$ & $70.73 \pm 4.31$ \\
\hline Both & $62.24 \pm 22.44$ & $74.80 \pm 19.14$ & 80.2 & $7 \pm 22.58$ & 70.8 & \pm 14.62 & 71.2 & \pm 16.78 & & $74.72 \pm 18.59$ & $72.29 \pm 16.22$ \\
\hline $\mathbf{F}(\mathbf{p})$ & $1.115(0.337)$ & $0.074(0.929)$ & 0.10 & $(0.897)$ & 0.56 & $(0.574)$ & 0.42 & $(0.654)$ & & $0.015(0.985)$ & $0.173(0.841)$ \\
\hline & ve you attended & completed any & educ & tion prog & $\mathrm{am} / \mathrm{w}$ & kshop o & $\operatorname{trans}$ & ultural n & 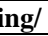 & ultural compete & e in the past? \\
\hline Yes & $72.35 \pm 13.47$ & $79.55 \pm 10.02$ & 82.6 & $7 \pm 11.38$ & 78.5 & \pm 12.38 & 71.2 & \pm 12.25 & & $78.72 \pm 8.27$ & $77.22 \pm 8.38$ \\
\hline No & $65.93 \pm 19.12$ & $72.61 \pm 16.32$ & 77.3 & $9 \pm 18.04$ & 72.3 & \pm 14.25 & 71. & \pm 16.24 & & $73.06 \pm 16.49$ & $72.36 \pm 14.68$ \\
\hline$t(p)$ & $1.030(0.309)$ & $1.325(0.192)$ & 0.91 & (0.368) & 1.28 & $(0.204)$ & 0.12 & $(0.902)$ & & $1.088(0.283)$ & $1.038(0.305)$ \\
\hline & & & & & & 0 you inc & ude ct & tural con & in in & our current teac & ing program? \\
\hline Yes & $68.27 \pm 18.20$ & $75.88 \pm 15.16$ & 79.7 & $3 \pm 16.99$ & 73.8 & \pm 13.40 & 72. & \pm 15.01 & & $75.41 \pm 14.67$ & $74.25 \pm 13.38$ \\
\hline No & $62.50 \pm 17.08$ & $64.06 \pm 12.14$ & 71.8 & $8 \pm 13.98$ & 73. & \pm 18.56 & 69. & 17.97 & & $68.18 \pm 17.19$ & $69.0 \pm 14.64$ \\
\hline$t(p)$ & $0.728(0.471)$ & $1.816(0.076)$ & 1.07 & $(0.289)$ & 0.06 & (0.948) & 0.34 & (0.732) & & $1.100(0.278)$ & $0.884(0.382)$ \\
\hline & & & & & whe & is the ley & $\mathrm{dof}$ & tural con & 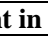 & our current teac & ing program? \\
\hline Fully Integrated & $73.33 \pm 16.69$ & $77.50 \pm 15.58$ & 84.2 & $8 \pm 16.14$ & 74.5 & \pm 15.03 & & \pm 17.12 & & $79.32 \pm 15.91$ & $76.95 \pm 15.23$ \\
\hline $\begin{array}{r}\text { Occasionally } \\
\text { mentioned }\end{array}$ & $64.17 \pm 20.70$ & $70.47 \pm 14.78$ & & $3 \pm 18.06$ & 70.9 & \pm 13.89 & & \pm 14.50 & & $71.14 \pm 15.75$ & $70.37 \pm 13.88$ \\
\hline Required course & $71.76 \pm 12.46$ & $86.11 \pm 10.26$ & 86. & $1 \pm 12.80$ & & $0 \pm 8.91$ & 73. & \pm 14.75 & & $80.56 \pm 7.37$ & $79.88 \pm 7.03$ \\
\hline $\begin{array}{cc}\text { Elective } & \begin{array}{c}\text { cultural } \\
\text { course }\end{array} \\
\end{array}$ & $66.67 \pm 0.0$ & $84.38 \pm 0.0$ & & $1.88 \pm 0.0$ & & $5.0 \pm 0.0$ & & $.38 \pm 0.0$ & & $75.0 \pm 0.0$ & $71.95 \pm 0.0$ \\
\hline $\mathbf{F}(\mathbf{p})$ & $0.733(0.539)$ & $2.906\left(0.047^{*}\right)$ & 1.55 & $(0.217)$ & 0.97 & $(0.417)$ & 0.73 & $(0.536)$ & & $1.257(0.303)$ & $1.344(0.275)$ \\
\hline & & & & you asse & your & udents' & ultura & beliefs a & & towards educat & nal learning? \\
\hline Yes & $69.44 \pm 17.26$ & $75.76 \pm 14.76$ & 79.9 & $2 \pm 17.68$ & 74.6 & \pm 14.31 & 72. & \pm 14.11 & & $75.83 \pm 15.31$ & $74.74 \pm 13.82$ \\
\hline No & $62.15 \pm 19.58$ & $70.31 \pm 16.40$ & 75.2 & $6 \pm 13.75$ & 71.5 & \pm 13.20 & 69. & \pm 18.47 & & $70.64 \pm 14.13$ & $70.27 \pm 12.53$ \\
\hline$t(p)$ & $1.209(0.233)$ & $1.063(0.294)$ & 0.82 & $(0.414)$ & 0.64 & $(0.521)$ & 0.60 & $(0.552)$ & & $1.024(0.312)$ & $0.981(0.332)$ \\
\hline
\end{tabular}

$\mathrm{t}$ : Student t-test

F: F for ANOVA test

$\mathrm{p}$ : $\mathrm{p}$ value for comparing between the studied categories *: Statistically significant at $\mathrm{p} \leq 0.05$

Supplementary Table-2: Comparison between Saudi and non-Saudi nurse educators regarding their culture competency

\begin{tabular}{|l|l|l|l|l|}
\hline Cultural Competence & $\begin{array}{l}\text { Non Saudi } \\
(\mathbf{n = 3 2})\end{array}$ & $\begin{array}{l}\text { Saudi } \\
(\mathbf{n = 1 3 )}\end{array}$ & $\mathbf{t}$ & $\mathbf{p}$ \\
\hline Cultural Encounters & $67.58 \pm 17.25$ & $67.31 \pm 20.40$ & 0.045 & 0.964 \\
\hline Cultural Desire & $74.61 \pm 14.59$ & $73.56 \pm 17.29$ & 0.208 & 0.836 \\
\hline Cultural Awareness & $79.30 \pm 13.28$ & $77.16 \pm 23.74$ & 0.385 & 0.702 \\
\hline Cultural Knowledge & $73.08 \pm 11.70$ & $75.70 \pm 18.80$ & 0.566 & 0.574 \\
\hline Cultural Skills & $71.88 \pm 13.70$ & $71.63 \pm 19.11$ & 0.047 & 0.962 \\
\hline Transcultural teaching behaviors & $74.64 \pm 12.62$ & $73.95 \pm 20.38$ & 0.139 & 0.890 \\
\hline Overall Cultural Competence & $73.55 \pm 11.25$ & $73.55 \pm 18.46$ & 0.001 & 0.999 \\
\hline
\end{tabular}

$\mathrm{t}$ : Student t-test

$\mathrm{p}: \mathrm{p}$ value for comparing between the studied categories 